Published in final edited form as:

Ment Health Phys Act. 2013 October ; 6(3): 165-171. doi:10.1016/j.mhpa.2013.06.002.

\title{
Indirect and direct relations between aerobic fitness, physical activity, and academic achievement in elementary school students
}

\author{
K. Lambourne ${ }^{a,}{ }^{*}$, D.M. Hansen ${ }^{b}$, A.N. Szaboc ${ }^{c}$, J. Lee ${ }^{d}$, S.D. Herrmann ${ }^{e}$, and J.E. Donnelly ${ }^{\dagger}$ \\ anternal Medicine, Cardiovascular Research Institute, Center for Physical Activity and Weight \\ Management, The University of Kansas Medical Center, 3901 Rainbow Blvd, Kansas City, \\ Kansas, 66160, USA. Katel@ku.edu \\ ${ }^{b}$ Department of Psychology and Research in Education, The University of Kansas, 1122 West \\ Campus Road, Lawrence, KS, 66045 USA. dhansen1@ku.edu \\ Internal Medicine, Cardiovascular Research Institute, Center for Physical Activity and Weight \\ Management, The University of Kansas Medical Center, 3901 Rainbow Blvd, Kansas City, \\ Kansas, 66160, USA. aszabo@ku.edu \\ ${ }^{d}$ Center for Research Methods and Data Analysis, The University of Kansas, 1425 Jayhawk \\ Boulevard, Watson RM 470, Lawrence, KS 66045 USA. jaehoon@ku.edu \\ eInternal Medicine, Cardiovascular Research Institute, Center for Physical Activity and Weight \\ Management, The University of Kansas Medical Center, 3901 Rainbow Blvd, Kansas City, \\ Kansas, 66160, USA. sherrmann@ku.edu \\ fInternal Medicine, Cardiovascular Research Institute, Center for Physical Activity and Weight \\ Management, The University of Kansas Medical Center, 3901 Rainbow Blvd, Kansas City, \\ Kansas, 66160, USA. jdonnelly@ku.edu
}

\section{Abstract}

BACKGROUND-There is evidence to suggest that increasing physical activity (PA) improves academic achievement (AA) in children and that aerobic fitness is associated with both cognitive function and AA. However, it is not known how these variables are interrelated and analyses with adequate control for socioeconomic variables are needed. It was hypothesized that PA would not directly affect AA but would have an indirect effect on AA through its effect on aerobic fitness. The purpose of this study was to test this hypothesized mediation using path analysis.

\footnotetext{
(C) 2013 Elsevier Ltd. All rights reserved.

*Author who will handle correspondence at all stages of refereeing and publication: Kate Lambourne, Internal Medicine, Cardiovascular Research Institute, Center for Physical Activity and Weight Management, University of Kansas Medical Center, 3901 Rainbow Blvd, Kansas City, Kansas, 66160, Phone: 785-864-5680, Fax: 785-864-2009, katel@ ku.edu.

${ }^{1}$ Because multiple-group analyses in multi-level SEM require a higher-level unit to appear in only one group, 2-level model and single-level model were fitted for betweengrade comparison and between-gender comparison, respectively (i.e., disaggregation of data).
} 
METHODS—Cross-sectional data including AA, aerobic fitness, and daily PA assessed through accelerometry were collected from a large sample $(N=687)$ of $2^{\text {nd }}$ and $3^{\text {rd }}$ grade students. Demographic data were assessed via parent self-report.

RESULTS-A total of 401 students wore the accelerometer for at least 10 hours on 3 days or more and were included in the final path analysis to evaluate potential relations among PA (predictor), aerobic fitness (mediator), and WIAT-III subtest standard scores (outcomes; i.e., reading, spelling, and mathematics). Findings showed a direct effect of PA on aerobic fitness ( $b=$ $0.009, p<0.001)$ and an indirect effect (mediation) of PA via fitness on math achievement $(b=$ $0.003, p<0.01)$ after controlling for student's grade, gender, body mass index, mother's education level, and household income, as well as intraclass correlations among classes and schools. Neither PA nor aerobic fitness were correlated with WIAT-III reading or spelling scores.

CONCLUSIONS-Mediation analysis indicated that PA exerted an influence on math achievement through its effects on aerobic fitness but was not associated with reading or spelling achievement scores.

\section{Keywords}

Path analysis; mediation; Weschler Individual Achievement Test-III; Progressive Aerobic Cardiovascular Endurance Run

\section{BACKGROUND}

Childhood obesity is prevalent in the United States (Ogden, 2010), presenting a major threat to public health. Childhood obesity has been associated with both physical health problems (Krebs \& Jacobson, 2003) and poorer academic achievement (AA) (Howie \& Pate, 2012; Judge \& Jahns, 2007). Increasing physical activity (PA) and aerobic fitness are often proposed as a way to improve children's health and AA but there has been some inconsistency across studies concerning the relation between PA, aerobic fitness, and AA. This is due in part to measurement and methodological issues (e.g., measuring only PA or aerobic fitness, lack of adequate control for socioeconomic variables), but the overall pattern of findings indicates either a positive or null association (Castelli, Hillman, Buck, \& Erwin, 2007; Centers for Disease Control and Prevention; Chaddock, Pontifex, Hillman, \& Kramer, 2011; Coe, Pivarnik, Womack, Reeves, \& Malina, 2006; Davis, 2011; Donnelly et al., 2009; Dwyer, Sallis, Blizzard, Lazarus, \& Dean, 2001). Rarely is a negative association reported (Ahamed et al., 2007; Centers for Disease Control and Prevention; Sallis et al., 1999; Tremblay, Inman, \& Willms, 2000). Missing from this literature is a clear understanding of how each indicator (PA and aerobic fitness) operate together and separately to influence AA.

Active children generally display healthier cardiovascular profiles (Boreham \& Riddoch, 2001), and past research has shown that aerobic fitness and PA are moderately correlated in this population (Pate, Dowda, \& Ross, 1990). In a cohort study of 248 children (ages 8-11), time spent in vigorous PA was correlated with $\mathrm{VO}_{2 \text { peak, }}$ a measure of aerobic fitness, in both boys and girls ( $r=0.32$ and $r=0.30$ respectively, both $p<0.05$ (Dencker et al., 2006).

However, few studies on the relation of PA, aerobic fitness, and AA have measured both PA and aerobic fitness. In studies that have, the associations with AA have been evaluated in 
separate models, thereby failing to statistically account for possible collinearity (e.g., shared variance of PA and aerobic fitness) (Dwyer et al., 2001). Additionally, the relationship between PA and aerobic fitness suggests mediated effects on AA (Welk \& Meredith, 2008). Specifically, the effect of PA on AA could be transmitted through its effect on aerobic fitness (Chaddock et al., 2011). Aerobic fitness reflects the capacity of the body to do physical work (Bray et al., 2009), and can be measured in children using maximal (American College of Sports Medicine, 2012) and sub-maximal exercise tests such as the Progressive Aerobic Cardiovascular Endurance Run (PACER) (Leger, Mercier, Gadoury, \& Lambert, 1988; Welk \& Meredith, 2008). Aerobic fitness is influenced by hereditary factors and lifestyle factors, including PA level (Bray et al., 2009). Several studies have demonstrated that aerobic fitness is associated with better cognitive function and AA (Chaddock et al., 2011; Hillman, Castelli, \& Buck, 2005; Voss et al., 2011; Welk \& Meredith, 2008). Research is needed to better understand the interrelationships between PA, aerobic fitness, and AA.

The purpose of the present study was to evaluate how both PA and aerobic fitness are related to AA in a sample of $2^{\text {nd }}$ and $3^{\text {rd }}$ grade students. Given the limitations in past research, this study included important controls for socioeconomic variables and separate measure of PA and aerobic fitness.

\section{METHODS}

\section{Participants}

Seventeen schools were recruited to participate in the present study, which is part of a larger investigation of the effects of physically active academic lessons on academic outcomes (NIH R01 DK085317). The parents of students in $2^{\text {nd }}$ and $3^{\text {rd }}$ grades received a flyer describing the study, including exclusion criteria and assessment procedures. Parents of students interested in participation provided their contact information to the school. Due to a large response, a random sample of $2^{\text {nd }}$ and $3^{\text {rd }}$ grade students (stratified by grade and gender) in each school was selected from those who provided parental consent/child assent to complete the outcome assessments used for this study, including AA, aerobic fitness, and daily PA. Participants also completed tests of cognitive function, anthropometrics, blood pressure, and blood chemistry for the larger study. The study was approved by the Human Subjects Committee at the University of Kansas.

\section{Procedure}

All assessments were completed at the respective schools by trained research staff blinded to study condition. More detail on the training of the staff is provided in the instrumentation section. Testing for this study was completed over the course of 2 days, with each visit lasting approximately 1 hour. The accelerometer was issued at one of the visits and collected at a later date. All of the measures were completed prior to the initiation of the exercise intervention for the larger study. 


\section{Instruments}

Demographics. Parents completed a demographic questionnaire that assessed the grade, age, gender, ethnicity, and race of their student, as well as the education level of the mother and household income.

Academic achievement (AA). AA was assessed using the Weschsler Individual Achievement Test-Third Edition (WIAT-III) (Wechsler, 2009). The WIAT-III was individually administered by research staff trained and supervised by a qualified coinvestigator. Following WIAT III score computation guidelines, three scores were generated for this study, based on five WIAT-III subtests (reading comprehension and oral reading fluency, spelling, and mathematics problem solving and numerical operations): composite reading (reading comprehension and oral reading fluency subtests), composite mathematics (mathematics problem solving and numerical operations subtests), and spelling. The test took approximately $40-50$ minutes to complete.

The research staff completed a 3-hour training delivered by the qualified co-investigator, and followed by several practice administrations and a passing grade on a WIAT scoring test. The initial tests administered by the research staff were supervised by the qualified coinvestigator and corrective feedback was provided if necessary. The WIAT-III was scored by the examiner and all tests were checked for accuracy by a trained investigator. Any discrepancy in scores between examiner and the trained investigator was resolved by the qualified co-investigator. Scores were entered into the WIAT-III computerized scoring assistant, which automatically disallowed out-of-range values and computes subtest and composite scores.

Aerobic fitness. Aerobic fitness was assessed using PACER (Welk \& Meredith, 2008) which is based on the 20-meter shuttle run (Leger et al., 1988). There is extensive literature describing the reliability and validity of the 20-meter PACER across several age groups (Carrel et al., 2012; Leger et al., 1988; Mechelen, Hlobil, \& Kemper, 1986; Welk \& Meredith, 2008). The 20-meter PACER is commonly used around the world in children of a wide age range (age $6-19$ years) as evidenced by a meta-analysis of 418,026 children in 37 countries (Olds, Tomkinson, Léger, \& Cazorla, 2006). Utilizing the 20-meter PACER test affords a greater ability to compare and contrast to a wider range of studies in this area. The 20-meter PACER will permit monitoring of aerobic fitness changes over the 3-year A + PAAC study as the children progress to $5^{\text {th }}$ and $6^{\text {th }}$ grade.

To perform the PACER, the student was instructed to run back and forth between 2 lines, 20-meters apart, as the time allowed. The student was paced by a beep recorded on a CD to indicate when he or she should reach each end of the 20-meter course. The pace began slowly and progressively increased. The test ended for each student when he or she failed to traverse the 20-meter distance in the time allotted on 2 occasions. Research staff were trained by a qualified co-investigator to identify and track when a student failed to traverse the required distance. Staff were supervised by a co-investigator with extensive experience administering the PACER. The longer a student continued (i.e., more laps) indicated a higher level of aerobic capacity. The measure used in the analysis was the total number of laps completed. 
Daily Physical Activity. The student wore an ActiGraph GT3X+ portable accelerometer (ActiGraph LLC, Pensacola, FL) on a belt over the non-dominant hip for 4 consecutive days (including 1 weekend day). Accelerometer data were collected and summarized in 1-minute epochs with a minimum of 10 hours of wear time constituting a valid monitored day.

ActiGraphs were distributed to each student on Wednesdays and Fridays and returned to the school following completion of the 4-day monitoring period. The measure for daily PA was the average ActiGraph counts/min over the 4-day period. Data were analyzed using custom software that was developed by a co-investigator for the larger trial.

\section{Data Analysis}

Four-hundred and one students wore the accelerometer for $\geq 3$ valid days and were retained for analysis. Study variables were examined for distributional properties and all were normally distributed. Correlation analysis examined the bivariate associations between the variables. This was followed by a series of multi-level structural equation modeling (SEM) analyses that evaluated the potential mediation relationships among daily PA (activity counts/min.; predictor), aerobic fitness (PACER laps; mediator), and AA (3 WIAT-III subtest standard scores; outcomes) accounting for the nested nature of data - i.e., students (level-1) nested within classes (level-2) nested within schools (level-3). Data included $<1 \%$ of missing observations ( $0-3.5 \%$ missing on the variables; see Tables 1 and 2$)$ and all available data were analyzed in the intentionto-treat approach.

Figure 1 depicts the hypothesized mediation model. Mediation was tested using the SEM approach that decomposes a total effect on an outcome into direct effects and indirect effects (Preacher, 2011; Preacher, Zyphur, \& Zhang, 2010). In Figure 1, the direct effects include the paths $a, b$, and $c^{\prime}$, while the indirect effect $a b$ (product of $a$ and $b$ ) represents the impact of the predictor on an outcome through the mediator. Following the conceptual framework that demonstrates the process primarily occurring at the student level, the higher-level components of this model estimated only random intercepts of the variables, thereby accounting for intraclass correlations among classes and schools. Student's grade, gender, body mass index (BMI), mother's education level, and household income were also included in the model as covariates but they are omitted from Figure 1 for the sake of simplicity. These covariates were allowed to predict the mediator and outcomes and correlate with each other. Similarly, the correlations among the outcomes were also estimated but they are not depicted in this figure.

The model parameters were estimated via the robust maximum likelihood (MLR) estimator implemented in Mplus 7 (Muthén \& Muthén, 1998-2012). The equitability of an indirect effect between $2^{\text {nd }}$ and $3^{\text {rd }}$ grades or between males and females was assessed by Wald chisquare test in multiple-group maximum likelihood (ML) analyses. ${ }^{1}$ Overall model fit was evaluated using Root Mean Square Error of Approximation (RMSEA) and Comparative Fit Index $(\mathrm{CFI})$, which are robust to departure from multivariate normality and insensitive to

Publisher's Disclaimer: This is a PDF file of an unedited manuscript that has been accepted for publication. As a service to our customers we are providing this early version of the manuscript. The manuscript will undergo copyediting, typesetting, and review of the resulting proof before it is published in its final citable form. Please note that during the production process errors may be discovered which could affect the content, and all legal disclaimers that apply to the journal pertain. 
sample size (Hu \& Bentler, 1998). Also, relative model fit was examined using Akaike Information Criterion (AIC) and adjusted Bayesian Information Criterion (aBIC) for model comparisons in which a subsequent model is not nested in a previous model.

\section{RESULTS}

Sample characteristics, including average BMI and the number of students in each grade, age, gender, ethnicity, race, education level of the mother, and household income, are shown in Table 1. Descriptive statistics for each of the study variables appear in Table 2. Several significant correlations between the variables were identified (Table 3).

The hypothesized mediation model provided acceptable model fit $(\mathrm{RMSEA}=0.064, \mathrm{CFI}=$ 0.956). The model results, displayed in Table 4 , showed a significant direct effect of PA on PACER laps $(a)$, a significant direct effect of PACER laps on math achievement $(b)$, and a significant indirect effect of PA on math achievement via PACER laps $(a b)$. Given the significant direct effect of PA on math achievement $\left(c^{\prime}\right)$, these findings indicate that the statistical impact of PA on math achievement was partially mediated by PACER laps - i.e., those children who were more physically active had higher levels of aerobic fitness and in turn, higher aerobic fitness was associated with higher achievement on the math score on the WIAT-III. This mediation effect did not differ between males $(a b=0.001)$ and females $(a b$ $=0.004)\left(\chi^{2}=2.00, p=0.16\right)$, but it was significantly stronger among students in $2^{\text {nd }}$ grade $(a b=0.008)$ compared to those in $3^{\text {rd }}$ grade $(a b=0.001)\left(\chi^{2}=5.89, p<0.05\right)$.

Following recommendations by Strout and Bolger (2002) and a reviewer, we evaluated the plausibility of the hypothesized mediation model by comparing it to other alternative models. These models included a mediation model in a different direction (AA $\rightarrow$ fitness $\rightarrow$ PA), a moderation model (the impact of PA on AA is modified by fitness, or vice versa; interaction between PA and fitness), and a simple regression model without mediation or moderation. Results indicated that none of these alternative models provided either acceptable fit (according to RMSEA and CFI) or better fit (according to AIC and aBIC) than the original mediation model, suggesting that the mediation process tested (PA $\rightarrow$ fitness $\rightarrow$ AA) has been reasonably hypothesized. In addition, although it was not expected theoretically, the results indicated that the mediator possibly acted as a suppressor; $c^{\prime}$ was opposite in sign to $a b$, which made the total effect $\left(c^{\prime}+a b\right)$ become very small ("inconsistent mediation"; MacKinnon, Krull, \& Lockwood, 2000). When fitness was held constant, higher levels of PA appeared associated with lower math achievement; we also observed that this reduction was greater at higher fitness levels (see Figure 2).

Among the covariates, mother's education level was positively associated with reading ( $p<$ $0.001)$, spelling $(p<0.05)$, and math $(p<0.01)$ scores, while household income was positively associated with math achievement $(p<0.05)$ and aerobic fitness $(p<0.001)$. BMI was negatively associated with aerobic fitness $(p<0.001)$ but not with all 3 AA scales.

\section{DISCUSSION}

The results of the multi-level SEM analyses in the present study demonstrated that PA had a direct (statistical) effect on aerobic fitness, which in turn had a direct effect on math scores. 
The effect of PA on math achievement was partially mediated by aerobic fitness. These relations were present after controlling for student's grade, gender, BMI, mother's education level, and household income. Neither PA nor aerobic fitness were directly associated with reading or spelling scores. These findings extend the current knowledge in the literature on the effects of PA on AA by considering both PA and aerobic fitness simultaneously while also controlling for several different socioeconomic variables.

Past research indicates that PA and aerobic fitness are generally positively associated with AA, but it has not evaluated how PA and aerobic fitness together and separately relate to AA. The results of this study suggest that PA may affect math achievement directly, as well as indirectly, through aerobic fitness, which is consistent with research on the relation of PA and aerobic fitness as well as on the relation between aerobic fitness, cognitive function and AA (Chaddock et al., 2011; Hillman et al., 2005; Welk, 2010; Welk \& Meredith, 2008).

The finding that PA and fitness had an impact on math scores but not the other scales on the WIAT is consistent with previous studies. For example, Davis et al. (2011) conducted a randomized controlled trial to examine the influence of participating in aerobic exercise on cognition and AA in elementary school children. This study showed that children who participated in 40 minutes of exercise per day experienced significant improvements in math achievement as compared to students in a sedentary control condition after controlling for race, parent education, and baseline score. In addition, Davis et al. found a trend in the exercise condition towards differences in brain activity within the prefrontal and parietal regions, areas which are associated with executive function. Executive function develops during childhood and is crucial for adaptive behavior and development (Best, Miller, \& Jones, 2009; Eslinger, 1996). Executive function is often related to one's AA in elementary school (Blair, 2002; Eigsti et al., 2006). Other research within the cognitive function literature indicates that children of lower mathematical ability have difficulties performing tasks that measure components of executive such as the ability to inhibit both prepotent information (Stroop interference) and learned strategies (Wisconsin Card Sorting Task; WCST) and maintaining information in working memory (Bull \& Scerif, 2001). The same may not true for other AA tasks such as reading and spelling, as reading is typically only associated with executive function in cases where cognitive dysfunction or a learning disability is present (Locascio, Mahone, Eason, \& Cutting, 2010). All of the students included in the present study were typically developing, which may help to explain the lack of association between aerobic fitness and reading and spelling. Together, these studies as well as others (Abigail et al.; Chaddock et al., 2011; Voss et al., 2011; Wu et al., 2011) suggest that participating in aerobic exercise that results in increases in fitness may help to improve executive function performance and math abilities.

Although it was not of initial theoretical interest, the current findings suggested the possibility of a suppression process among PA, fitness, and AA. This suppression process could explain why relation of theoretical interest in this study (i.e., PA $\rightarrow$ AA) was not strong (Strout \& Bolger, 2002). Thus, given the empirical estimate of $c^{\prime}$ that was negative and significantly different from zero, the total effect should be interpreted with caution (MacKinnon et al., 2000; Shrout \& Bolger, 2002). In order to investigate the nature 
(mediation or suppression) of the interrelationships among PA, aerobic fitness, and AA, future research is needed.

The findings further support efforts to improve AA by increasing levels of aerobic fitness. PA guidelines for children currently recommend about one hour of PA each day, with most of this time being spent in moderate to vigorous levels of activity (Biddle, Cavill, \& Sallis, 1998; "Physical activity guidelines advisory committee report to the Secretary of Health and Human Services, 2008,"). Public schools are a promising environment to target PA and aerobic fitness levels through both classroom-based activity and physical education classes. In a recent study, Reed et al. (2008) examined the effect of 'Action Schools! British Columbia' (AS! BC) on aerobic fitness measured by PACER. The AS! BC model was consistent with the concept of 'active schools' (Fox, 2004) and was intended to deliver 15 minutes of extra moderate intensity physical daily in the classroom (goal of 75 minutes/ week in addition to two 40-minute PE classes). This resulted in a $20 \%$ greater increase in aerobic fitness of students in the intervention versus students in control schools. Interestingly, this increase in aerobic fitness had no impact on standardized achievement tests. In a related study by Reed et al. (2010), PA was integrated into elementary school curriculum to determine if active lessons had an impact on cognition and AA. When compared to a control group, the children who received the PA integrated lessons demonstrated enhanced fluid intelligence and certain academic achievement scores (e.g. social studies). Findings of the present study suggest that future research examine this relation further in longitudinal studies and if changes in fitness impact AA, to investigate how much PA is enough to enhance aerobic fitness and AA across a student population.

Findings from past research on the relation of PA, aerobic fitness, and AA have been inconsistent due, in part, to a lack of appropriate control variables (Howie \& Pate, 2012). In at least one study, significant associations between PA, aerobic fitness, and AA became nonsignificant when SES was included as a control variable (Judge \& Jahns, 2007). In addition, past studies have often included only a single indicator of SES, masking potential associations. In the present study, students' grade, gender, BMI, mothers' education level, and household income were controlled in the analysis, eliminating one potential source of confounding effects on the findings. It is also worth noting the different patterns of associations between mother's education/household income and PA, aerobic fitness, and AA. Mother's education was associated with reading and math achievement and income was associated with math achievement and aerobic fitness, which suggests that it is important in future studies to use multiple indicators of SES as controls.

\section{Limitations}

The cross-sectional design of this study precludes causal conclusions about whether PA or aerobic fitness has an independent effect on AA. Further, there is limited validity evidence available for the 20-meter PACER in 7-8 year old children. The potential for confounding by motivation to perform or other residual confounding is present. Further, the lack of significant correlations between PA and AA could reflect a "delayed effect"- because measured concurrently with aerobic fitness, recent PA levels may not have yet had an effect on aerobic fitness, and subsequently on AA. Future longitudinal studies and interventions 
should be conducted to better determine how changes in PA and aerobic fitness influence AA in children.

Despite the rapidly growing body of research surrounding the importance of PA and aerobic fitness for cognitive function, academic and general well-being in children, budget cuts in education as well as a demand for increasing instructional time and standardized test scores have resulted in decreases in physical education and other non-core academic courses. This means that PA must be obtained at other times during the day to elicit improvements in aerobic fitness (Center on Education Policy, 2008). Alternatively, PA interventions applied during academic lessons have been shown to increase overall PA and attenuate increases in body mass and are also associated with improvements in AA scores (Donnelly et al., 2009; Donnelly \& Lambourne, 2011). Further, many studies show that PA breaks in classroom instruction resulted in positive changes in classroom behavior, concentration, and math solving performance (Ahamed et al., 2007; Lowden, Powney, Davidson, \& James, 2001; Maeda, 2003; Molloy, 1989; Norlander, Moas, \& Archer, 2004).Therefore, using physically active academic lessons and providing activity breaks to children may be important avenues to improve aerobic fitness and enhance AA.

\section{REFERENCES}

Abigail F, James B, James P, Christine W, John MC, John R. Effects of a physical education intervention on cognitive function in young children: randomized controlled pilot study. BMC Pediatrics. 11

Ahamed Y, Macdonald H, Reed K, Naylor PJ, Liu-Ambrose T, McKay H. School-based physical activity does not compromise children's academic performance. Med Sci Sports Exerc. 2007; 39(2): 371-376. [PubMed: 17277603]

American College of Sports Medicine. Resource Manual for Guidelines for Exercise Testing and Prescription. 6th ed.. Philadelphia, PA: Wolter Kluwer; 2012.

Best JR, Miller PH, Jones LL. Executive functions after age 5: Changes and correlates. Developmental Review. 2009; 29(3):180-200. [PubMed: 20161467]

Biddle S, Cavill N, Sallis JF. Young and active?: Young people and health-enhancing physical activity: evidence and implications: Health Education Authority. 1998

Blair C. School readiness. Integrating cognition and emotion in a neurobiological conceptualization of children's functioning at school entry. Am Psychol. 2002; 57(2):111-127. [PubMed: 11899554]

Boreham C, Riddoch C. The physical activity, fitness and health of children. J Sports Sci. 2001; 19(12):915-929. [PubMed: 11820686]

Bray MS, Hagberg JM, Perusse L, Rankinen T, Roth SM, Wolfarth B, Bouchard C. The human gene map for performance and health-related fitness phenotypes: the 2006-2007 update. Med Sci Sports Exerc. 2009; 41(1):35-73. [PubMed: 19123262]

Bull R, Scerif G. Executive functioning as a predictor of children's mathematics ability: Inhibition, switching, and working memory. Developmental neuropsychology. 2001; 19(3):273-293. [PubMed: 11758669]

Carrel, Aaron L.; Bowser, John; White, Doug; Moberg, D. Paul; Weaver, Brian; Hisgen, Jon; Allen, David B. Standardized Childhood Fitness Percentiles Derived from School-Based Testing. The Journal of Pediatrics. 2012; 161(1):120-124. doi: http://dx.doi.org/10.1016/j.jpeds.2012.01.036. [PubMed: 22364851]

Castelli DM, Hillman CH, Buck SM, Erwin HE. Physical fitness and academic achievement in thirdand fifth-grade students. J Sport Exerc Psychol. 2007; 29(2):239-252. [PubMed: 17568069]

Center on Education Policy. Instructional time in elementary schools: A closer look at changes for specific subjects. 2008. Retrieved 2/1/2013, from www.cep-dc.org/_data/in_0001/resources/live/ InstructionalTimeFeb2008.pdf. 
Centers for Disease Control and Prevention. The association between school-based physical activity, including physical education, and academic performance. $2010 \mathrm{Apr}$.

Chaddock L, Pontifex MB, Hillman CH, Kramer AF. A review of the relation of aerobic fitness and physical activity to brain structure and function in children. J Int Neuropsychol Soc. 2011; 17(6): 975-985. [PubMed: 22040896]

Coe DP, Pivarnik JM, Womack CJ, Reeves MJ, Malina RM. Effect of physical education and activity levels on academic achievement in children. Med Sci Sports Exerc. 2006; 38(8):1515-1519. [PubMed: 16888468]

Davis CL. Exercise improves executive function and achievement and alters brain activation in overweight children: A randomized, controlled trial. Health Psychol. 2011; 30(1)

Davis CL, Tomporowski PD, McDowell JE, Austin BP, Miller PH, Yanasak NE, Naglieri JA. Exercise improves executive function and achievement and alters brain activation in overweight children: a randomized, controlled trial. Health Psychology. 2011; 30(1):91. [PubMed: 21299297]

Dencker, Magnus; Thorsson, Ola; Karlsson, MagnusK; Lindén, Christian; Svensson, Jesper; Wollmer, Per; Andersen, LarsBo. Daily physical activity and its relation to aerobic fitness in children aged 8-11 years. European Journal of Applied Physiology. 2006; 96(5):587-592. [PubMed: 16408232]

Donnelly JE, Greene JL, Gibson CA, Smith BK, Washburn RA, Sullivan DK, Williams SL. Physical Activity Across the Curriculum (PAAC): a randomized controlled trial to promote physical activity and diminish overweight and obesity in elementary school children. Prev Med. 2009; 49:336-341. [PubMed: 19665037]

Donnelly JE, Lambourne K. Classroom-based physical activity, cognition, and academic achievement. Prev Med. 2011; 52(1):31.

Dwyer T, Sallis JF, Blizzard L, Lazarus R, Dean K. Relation of academic performance to physical activity and fitness in children. Ped Exerc Sci. 2001; 13:225-237.

Eigsti IM, Zayas V, Mischel W, Shoda Y, Ayduk O, Dadlani MB, Casey BJ. Predicting cognitive control from preschool to late adolescence and young adulthood. Psychological Science. 2006; 17(6):478-484. [PubMed: 16771797]

Eslinger PJ. Conceptualizing, describing, and measuring components of executive function: A summary. 1996

Fox KR. Childhood obesity and the role of physical activity. The Journal of the Royal Society for the Promotion of Health. 2004; 124(1):34-39. [PubMed: 14971191]

Hillman CH, Castelli DM, Buck SM. Aerobic fitness and neurocognitive function in healthy preadolescent children. Med Sci Sports Exerc. 2005; 37(11):1967-1974. [PubMed: 16286868]

Howie EK, Pate R. Physical activity and academic achievement in children: A historical perspective. Journal of Sport and Health Science. 2012

$\mathrm{Hu}$, Li-tze; Bentler, Peter M. Fit indices in covariance structure modeling: Sensitivity to underparameterized model misspecification. Psychological Methods. 1998; 3(4):424-453.

Judge S, Jahns L. Association of overweight with academic performance and social and behavioral problems: an update from the early childhood longitudinal study. J Sch Health. 2007; 77(10):672678. [PubMed: 18076412]

Krebs NF, Jacobson MS. Prevention of pediatric overweight and obesity. Pediatrics. 2003; 112(2): 424-430. [PubMed: 12897303]

Leger LA, Mercier D, Gadoury C, Lambert J. The multistage 20 metre shuttle run test for aerobic fitness. J Sports Sci. 1988; 6(2):93-101. [PubMed: 3184250]

Locascio, Gianna; Mahone, E. Mark; Eason, Sarah H.; Cutting, Laurie E. Executive Dysfunction Among Children With Reading Comprehension Deficits. Journal of Learning Disabilities. 2010; 43(5):441-454. [PubMed: 20375294]

Lowden K, Powney J, Davidson J, James C. The Class Moves! Pilot in Scotland and Wales: An evaluation. Research report series. Scottish Council for Research in Education. 2001

MacKinnon DP, Krull JL, Lockwood CM. Equivalence of the Mediation, Confounding and Suppression Effect. Prevention Science. 2000; 1(4):173-181. [PubMed: 11523746]

Maeda JK. Can academic success come from five minutes of physical activity? Brock Education Journal. 2003; 13(1):14-22. 
Mechelen W, Hlobil H, Kemper HCG. Validation of two running tests as estimates of maximal aerobic power in children. European Journal of Applied Physiology and Occupational Physiology. 1986; 55(5):503-506. [PubMed: 3769907]

Molloy GN. Chemicals, exercise and hyperactivity: A short report. Int J of Disability, Dev and Educ. 1989; 36(1):57-61.

Muthén, LK.; Muthén, BO. Mplus User's Guide. Seventh Edition. Los Angeles, CA: Muthén \& Muthén; 1998-2012.

Norlander T, Moas L, Archer T. Noise and stress in primary and secondary children: noise reduction and increased concentration ability through a short but regular exercise program. School Effectiveness and School Improvement. 2004; 16(1):91-99.

Ogden CL. Prevalence of High Body Mass Index in US Children and Adolescents, 2007-2008. JAMA. 2010; 303(3):242-249. [PubMed: 20071470]

Olds, Tim; Tomkinson, Grant; Léger, Luc; Cazorla, Georges. Worldwide variation in the performance of children and adolescents: An analysis of 109 studies of the 20-m shuttle run test in 37 countries. Journal of Sports Sciences. 2006; 24(10):1025-1038. [PubMed: 17115514]

Pate RR, Dowda M, Ross JG. Association between physical activity and physical fitness in American children. American Journal of Diseases of Children. 1990; 144:1123-1129. [PubMed: 2403093]

Physical activity guidelines advisory committee report to the Secretary of Health and Human Services. 2008. http:www.health.gov/PAGuidelines/committeereport.aspx.

Preacher KJ. Multilevel SEM Strategies for Evaluating Mediation in Three-Level Data. Multivariate Behavioral Research. 2011; 46(4):691-731.

Preacher KJ, Zyphur MJ, Zhang Z. A general multilevel SEM framework for assessing multilevel mediation. Psychological methods. 2010; 15(3):209. [PubMed: 20822249]

Reed JA, Einstein G, Hahn E, Hooker SP, Gross VP, Kravitz J. Examining the impact of integrating physical activity on fluid intelligence and academic performance in an elementary school setting: a preliminary investigation. J Phys Act Health. 2010; 7(3):343-351. [PubMed: 20551490]

Reed KE, Warburton DER, Macdonald HM, Naylor PJ, McKay HA. Action Schools! BC: A schoolbased physical activity intervention designed to decrease cardiovascular disease risk factors in children. Preventive medicine. 2008; 46(6):525-531. [PubMed: 18377970]

Sallis JF, McKenzie TL, Kolody B, Lewis M, Marshall S, Rosengard P. Effects of healthrelated physical education on academic achievement: project SPARK. Res Q Exerc Sport. 1999; 70(2): 127-134. [PubMed: 10380244]

Tremblay MS, Inman JW, Willms JD. The relationship between physical activity, selfesteem, and academic achievement in 12-year-old children. Pediatric Exercise Sci. 2000; 12:312-323.

Voss MW, Chaddock L, Kim JS, Vanpatter M, Pontifex MB, Raine LB, Kramer AF. Aerobic fitness is associated with greater efficiency of the network underlying cognitive control in preadolescent children. Neuroscience. 2011; 199:166-176. [PubMed: 22027235]

Wechsler, D. Wechsler Individual Achievement Test 3rd Edition (WIAT III). London: The Psychological Corp; 2009.

Welk GJ. The association of health-related fitness with indicators of academic performance in Texas schools. Res. Q Exerc. Sport. 2010; 81(supplement 2):16S-23S.

Welk, GJ.; Meredith, MD. Fitnessgram/Activitygram Reference Guide. Dallas TX: The Cooper Institute; 2008.

Wu CT, Pontifex MB, Raine LB, Chaddock L, Voss MW, Kramer AF, Hillman CH. Aerobic fitness and response variability in preadolescent children performing a cognitive control task. Neuropsychology. 2011; 25(3):333. [PubMed: 21443340] 


\section{HIGHLIGHTS}

- Evidence suggests that increasing PA and fitness improves AA in children.

- Evaluation of these variables with adequate control for SES is needed.

- Path analyses examined PA, fitness, and AA in a large sample of $2^{\text {nd }}$ and $3^{\text {rd }}$ graders.

- PA had an indirect effect (mediation) of PA on AA via fitness on mathematics.

- PA and fitness were not associated with reading or spelling achievement scores 


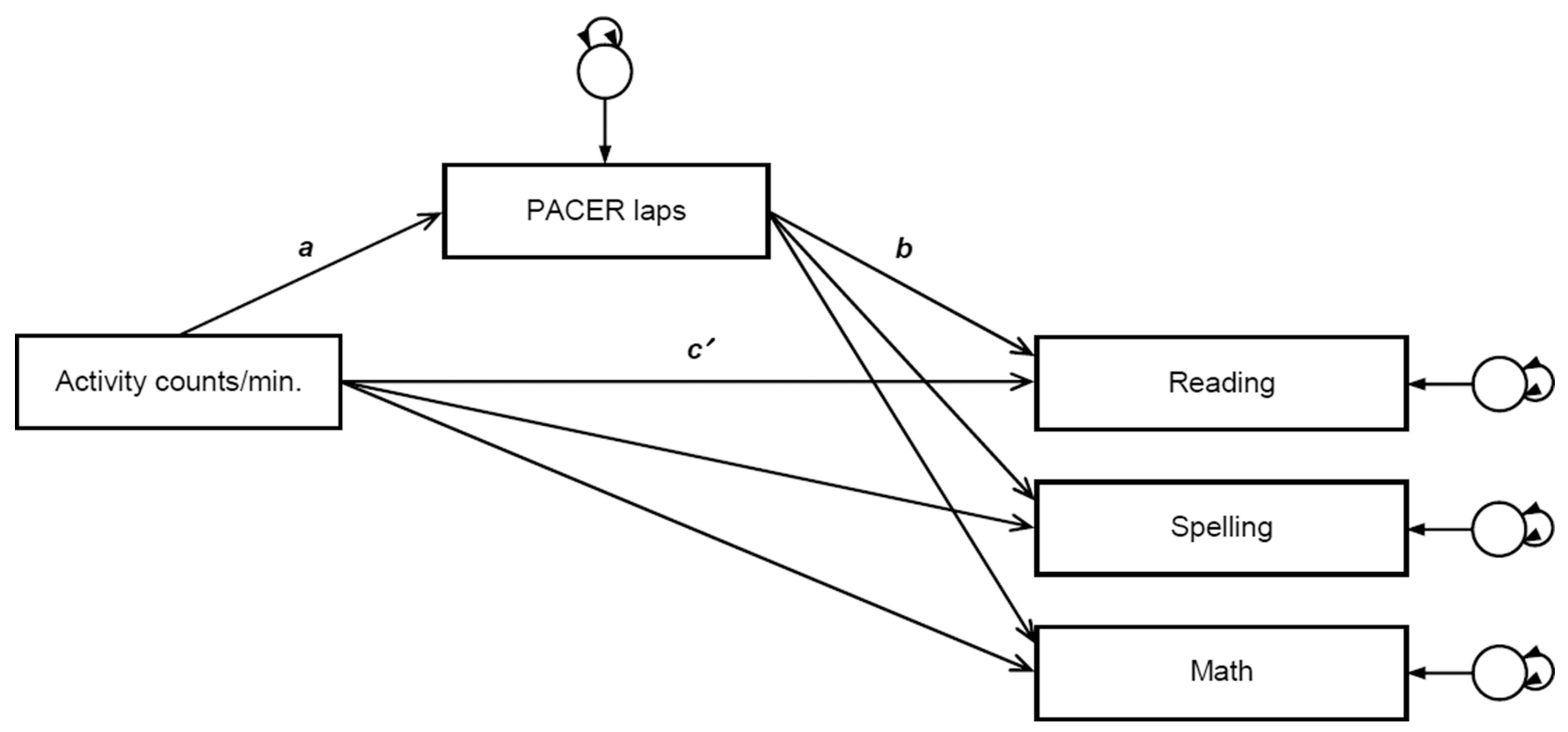

Figure 1.

Hypothesized Mediation Relationships

Note. The circles with a double-headed arrow represent the residual variances of variables. 


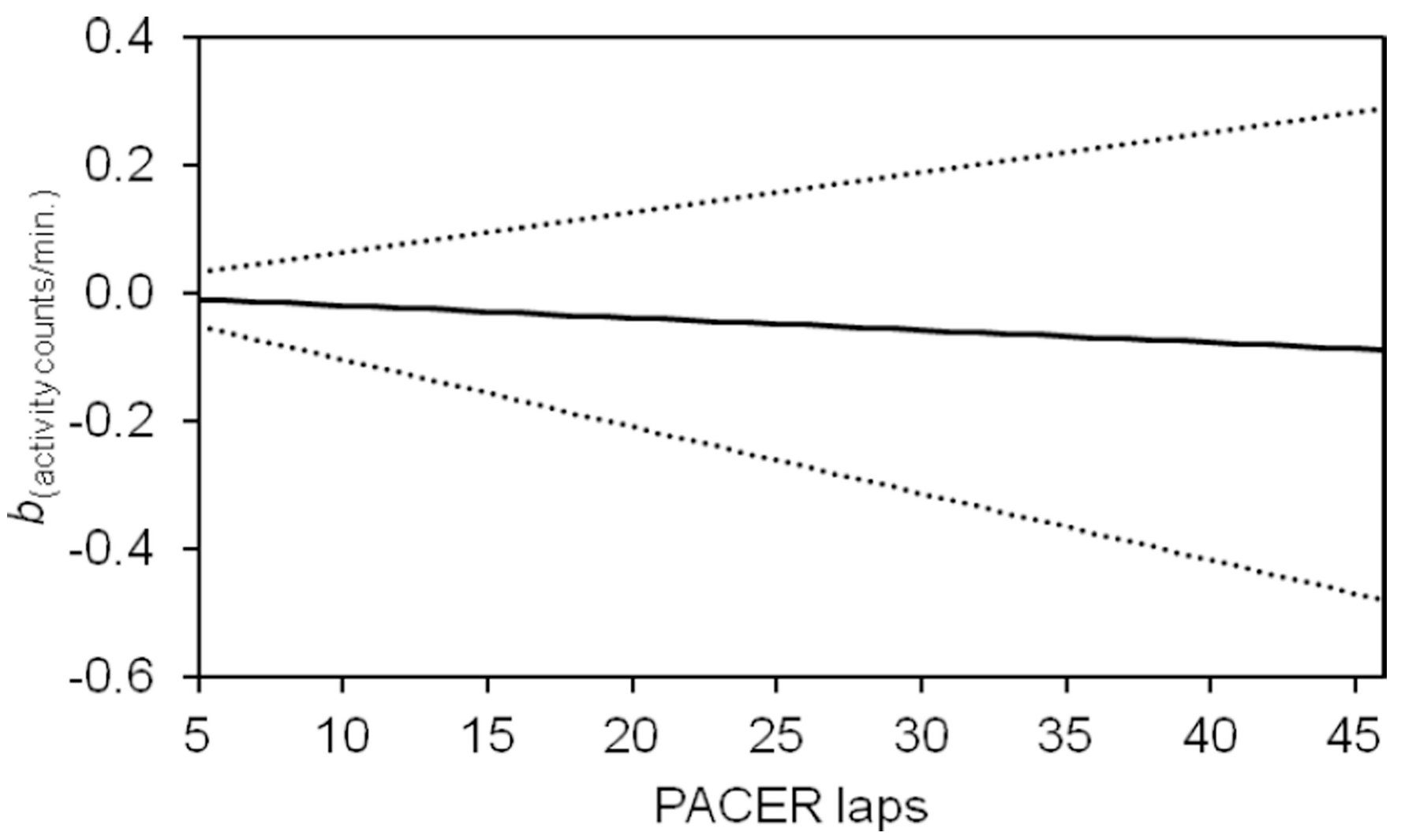

Figure 2.

Effects of Activity Counts/minute on Math Achievement Conditional on PACER Laps

Note. The solid line represents the impact of activity counts/min on mathematics achievement at different values of PACER laps. The dotted lines represent 95\% biascorrected confidence intervals derived from 5,000 bootstrap samples. These regression coefficients were estimated from a single-level regression model that accounts for student's grade, gender, BMI, mother's education level, and household income. 


\section{Table 1}

\section{Sample Characteristics}

\begin{tabular}{|c|c|c|}
\hline Variable & $N(M)$ & $\%(S D)$ \\
\hline \multicolumn{3}{|l|}{ Grade } \\
\hline Grade 2 & 200 & $49.9 \%$ \\
\hline Grade 3 & 201 & $50.1 \%$ \\
\hline Age & 7.57 & .58 \\
\hline 6 yrs. & 2 & $.5 \%$ \\
\hline $7 \mathrm{yrs}$ & 184 & $45.9 \%$ \\
\hline 8 yrs. & 200 & $49.9 \%$ \\
\hline 9 yrs. & 15 & $3.7 \%$ \\
\hline \multicolumn{3}{|l|}{ Gender } \\
\hline Male & 185 & $46.1 \%$ \\
\hline Female & 216 & $53.9 \%$ \\
\hline \multicolumn{3}{|l|}{ Ethnicity } \\
\hline Not Hispanic/Latino & 346 & $86.3 \%$ \\
\hline Hispanic/Latino & 36 & $9.0 \%$ \\
\hline Unknown & 10 & $2.5 \%$ \\
\hline Refused/missing & 9 & $2.2 \%$ \\
\hline \multicolumn{3}{|l|}{ Race } \\
\hline White & 335 & $83.5 \%$ \\
\hline Black/African American & 11 & $2.7 \%$ \\
\hline Native Hawaiian/Pacific Islander & 0 & $.0 \%$ \\
\hline Asian & 7 & $1.7 \%$ \\
\hline American Indian/Alaska Native & 5 & $1.2 \%$ \\
\hline Two or more races & 39 & $9.7 \%$ \\
\hline Unknown & 1 & $.2 \%$ \\
\hline Refused/missing & 3 & $.7 \%$ \\
\hline \multicolumn{3}{|l|}{ Education (mother) } \\
\hline Less than high school & 4 & $1.0 \%$ \\
\hline Some high school & 14 & $3.5 \%$ \\
\hline Completed high school & 41 & $10.2 \%$ \\
\hline Some college/Associate's degree & 127 & $31.7 \%$ \\
\hline Bachelor's degree & 134 & $33.4 \%$ \\
\hline Advanced degree & 79 & $19.7 \%$ \\
\hline Refused/missing & 2 & $.5 \%$ \\
\hline \multicolumn{3}{|l|}{ Household income } \\
\hline$<\$ 10,000$ & 20 & $5.0 \%$ \\
\hline$\$ 10,000-\$ 20,000$ & 18 & $4.5 \%$ \\
\hline$\$ 21,000-\$ 30,00$ & 38 & $9.5 \%$ \\
\hline$\$ 31,000-\$ 30,00$ & 30 & $7.5 \%$ \\
\hline$\$ 41,000-\$ 30,00$ & 40 & $10.0 \%$ \\
\hline
\end{tabular}




\begin{tabular}{|c|c|c|c|}
\hline & Variable & $N(M)$ & $\%(S D)$ \\
\hline & $\$ 51,000-\$ 30,00$ & 29 & $7.2 \%$ \\
\hline & $\$ 61,000-\$ 30,00$ & 30 & $7.5 \%$ \\
\hline & $\$ 71,000-\$ 30,00$ & 37 & $9.2 \%$ \\
\hline & $\$ 81,000-\$ 30,00$ & 25 & $6.2 \%$ \\
\hline & $\$ 91,000-\$ 30,00$ & 35 & $8.7 \%$ \\
\hline & $>\$ 100,000$ & 85 & $21.2 \%$ \\
\hline & Refused/missing & 14 & $3.5 \%$ \\
\hline & BMI & 17.43 & 3.01 \\
\hline
\end{tabular}

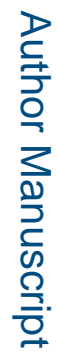

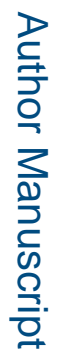

Ment Health Phys Act. Author manuscript; available in PMC 2015 May 15. 


\section{Table 2}

Task Descriptive Characteristics

\begin{tabular}{lcrr}
\hline Variable & $\boldsymbol{N}$ & $\boldsymbol{M}$ & $\boldsymbol{S D}$ \\
\hline PACER laps & 400 & 16.63 & 8.66 \\
Activity counts/min. & 401 & 560.87 & 181.84 \\
Reading & 394 & 102.50 & 13.87 \\
Spell & 398 & 101.33 & 11.67 \\
Math & 398 & 105.01 & 12.19 \\
\hline
\end{tabular}

Note. WIAT-III scores are normed with $M=100$ and $S D=15$ 


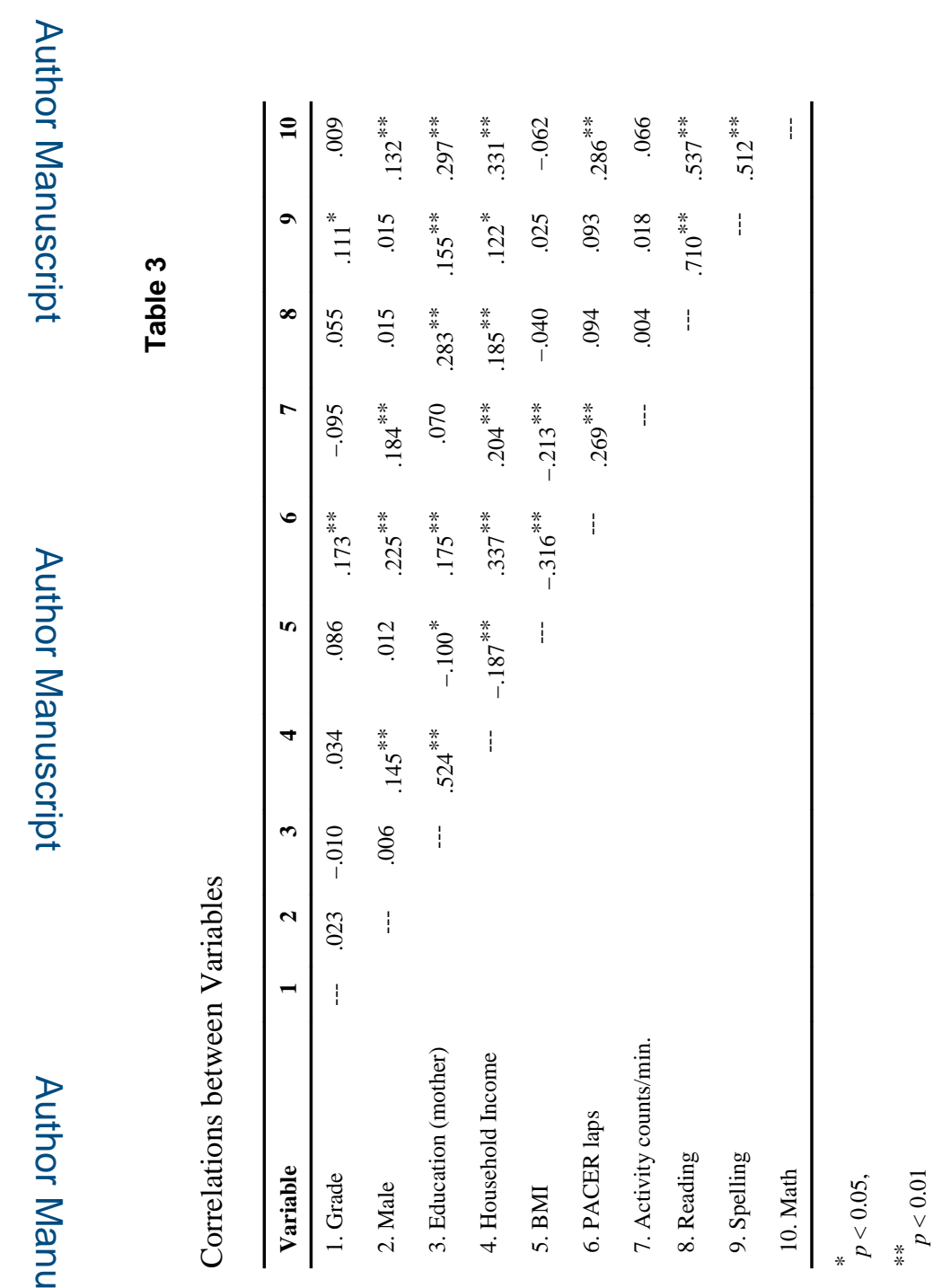

Ment Health Phys Act. Author manuscript; available in PMC 2015 May 15. 
Table 4

Direct and Indirect Effect Estimates and Intraclass Correlation Estimates

\begin{tabular}{lrrrr}
\hline & $\mathbf{a}$ & $\mathbf{b}$ & $\mathbf{c}^{\prime}$ & $\mathbf{a b}$ \\
\hline & $0.009^{* *}$ & & & \\
Reading & & 0.071 & -0.007 & 0.001 \\
Spelling & & 0.093 & -0.002 & 0.001 \\
Math & & $0.325^{* *}$ & $-0.007^{*}$ & $0.003^{*}$ \\
& $\mathrm{ICC}_{2}$ & $\mathrm{ICC}_{3}$ & & \\
\hline PACER laps & 0.007 & 0.042 & & \\
Activity counts/min. & 0.031 & 0.060 & & \\
Reading & 0.076 & 0.027 & & \\
Spelling & 0.049 & 0.053 & & \\
Math & 0.067 & 0.029 & & \\
\hline
\end{tabular}

Note. $a=$ direct effect of activity counts/min. (predictor) on PACER laps (mediator); $b=$ direct effect of PACER laps on an outcome; $c^{\prime}=$ direct effect of activity counts/min. on an outcome; $a b=$ indirect effect of activity counts $/ \mathrm{min}$. on an outcome via PACER laps. ICC $2=$ intraclass correlation at the class level; ICC $3=$ intraclass correlation at the school level.

* $p<0.05$

*** $p<0.01$. 